\title{
Época de semeadura no Potencial produtivo de Soja em Uberlândia-MG
}

\section{Sowing time on Soybean yield potential in Uberlândia-MG}

\author{
Flávia Aparecida Amorim¹; Osvaldo Toshiyuki Hamawaki²*; Larissa Barbosa de \\ Sousa $^{3}$; Regina Maria Quintão Lana ${ }^{4}$ Cristiane Divina Lemes Hamawaki ${ }^{5}$
}

\section{Resumo}

O trabalho foi feito em Uberlândia, com o objetivo de avaliar o comportamento de sete cultivares de soja em quatro épocas distintas de semeadura: 30 de Outubro, 15 de Novembro, 14 e 31 de Dezembro, na safra 2001/02. As cultivares utilizadas foram: DM-118 de ciclo precoce, DM-247, DM-Vitória, DM-339, de ciclo semitardio e DM-309, DM-98C81 e DM-Nobre de ciclo tardio. O delineamento utilizado foi o de blocos casualizados em esquema fatorial (7 cultivares x 4 épocas) com três repetições. As características avaliadas foram: produtividade, número de dias para floração e maturação, altura de plantas na maturação, inserção da primeira vagem e acamamento. Para a maioria das cultivares, a semeadura realizada a partir de 14 de dezembro na região de Uberlândia provocou queda na produtividade, tanto para as cultivares mais precoces quanto para mais tardia, DM Vitória, quando comparada a semeadura em 30 de outubro. $\mathrm{O}$ período para o florescimento, maturação e a altura de plantas interferiram na produtividade. Há decréscimo de altura de planta e número de dias para a floração, à medida que se atrasa a semeadura.

Palavras-chave: Cultivares, soja, cerrado, fotoperíodo

\begin{abstract}
The work was done in Uberlândia (MG) to evaluate the performance of seven soybeans cultivars sowed in four different times: October $30^{\text {th }}$, November $15^{\text {th }}$, December $14^{\text {th }}$ and $31^{\text {st }}$ during the $2001 / 2002$ season. The cultivars utilized were: DM-118 early-maturing, DM-247, DM-Victoria, DM-339, medium late cycle and DM-309, DM-98C81 and DM-Noble cycle Late. The statistical design was a randomized blocks in a factorial scheme ( 7 cultivars $\mathrm{x} 4$ times) with three replications. The evaluated characteristics were: yield, number of days for flowering, number of days for maturing, plant height, first bean height and plant laying. For the most evaluated cultivars, sowing beyond December $14^{\text {th }}$ in Uberlandia region presented yield losses for earlier cultivars as DM-118 as well for the later ones as DM Vitória, compared to sowing in 30th October. The time for flowering and maturing and plant height had effect on the yield. Key words: Cultivars, soybean, savanna, photoperiod
\end{abstract}

\section{Introdução}

Com a importância da soja como fator sócio econômico, pesquisas vêm sendo dirigidas no sentido de se alcançar maiores produtividades, associadas à redução nos custos de produção. No Brasil, a soja é cultivada em todas as regiões (ROCHA et al., 2006; DIAS, 2007), devido ao desenvolvimento de tecnologia nacional de produção como, por exemplo, o desenvolvimento

\footnotetext{
1 Eng $^{\mathrm{a}}$ Agr $^{\mathrm{a}}$, Mestre pela Universidade Federal de Uberlândia, UFU, Uberlândia, MG. E-mail: prograsojaufu@yahoo.com.br

2 Prof. Dr. da UFU, Uberlândia, MG. E-mail: osvaldohamawaki@yahoo.com.br

3 Doutoranda em Fitotecnia: Melhoramento de Plantas - Soja, UFU, Uberlândia, MG. E-mail: larissaufpi@ig.com.br

4 Prof $^{a}$ Dr $^{a}$ curso de Agronomia da UFU, Uberlândia, MG. E-mail: rmlana@umuarama.ufu.br

5 Prof ${ }^{\text {a }}$ Mestre em Inteligência Artificial, Universidade Presidente Antônio Carlos, UNIPAC. E-mail: crishamawaki@yahoo.com. br

* Autor para correspondência
} 
de cultivares adaptadas a diferentes ambientes.

Caracteres quantitativos como: componentes de rendimento (número de vagens por planta, número de grãos por vagem e massa dos grãos), altura de planta, duração do ciclo e produtividade, são os mais importantes na escolha das cultivares para cultivo e as mais influenciadas pelo manejo (PEIXOTO et al., 2000).

Toda e qualquer produção vegetal que vise à máxima produtividade econômica fundamentase na perfeita integração de três fatores: a planta, o ambiente de produção e o manejo (CÂMARA; HEIFFIG, 2000). Logo, as variedades de soja apresentam ampla diversidade genética quanto à sua área de adaptação, devido à sensibilidade ao fotoperíodo e à temperatura (CÂMARA, 1992).

A soja é sensível à duração das horas de luz do dia, florescendo quando o comprimento dos dias é inferior a determinado valor, denominado fotoperíodo crítico (EMBRAPA, 2008). No entanto, segundo Rodrigues et al. (2001), a sensibilidade fotoperiódica da soja varia com o genótipo e, nas cultivares mais sensíveis, a resposta ao fotoperíodo é quantitativa e não absoluta, o que significa que a floração ocorrerá de qualquer modo.

Embora a capacidade produtiva de uma planta dependa essencialmente da sua constituição genética, a exteriorização dessa característica agronômica fica subordinada às condições do ambiente em que ela se encontra (URBEN FILHO; SOUZA, 1993), sendo de grande importância na cultura da soja os atributos químicos dos solos (SCHONINGER et al., 2010).

Segundo Barros et al. (2003), a época de semeadura é definida por um conjunto de fatores ambientais que reagem entre si e interagem com a planta, causando variação na produção e afetando outras características agronômicas. Semeadas em diferentes épocas, as cultivares expressam suas potencialidades em relação às condições do ambiente, as quais mudam no espaço e no tempo. Como as cultivares podem responder diferencialmente ao ambiente, as indicações da melhor época para cada uma delas devem ser precedidas de ensaios regionalizados, conduzidos em mais de uma época de semeadura.

A época de semeadura é também um fator de elevada importância, uma vez que, além do rendimento, afeta também, e de modo acentuado, a arquitetura e comportamento da planta. Pesquisas realizadas no Brasil demonstraram que a época de semeadura é a variável que produz maior impacto sobre o rendimento da cultura da soja (PEIXOTO et al., 2000). Semeadura em época inadequada pode causar redução drástica no rendimento, bem como dificultar a colheita mecânica de tal modo que as perdas, nesta operação, possam chegar a níveis muito elevados. Isto, porque ocorrem alterações na altura da planta, altura de inserção das primeiras vagens, número de ramificações e acamamento (KOMORI, HAMAWAKI, ALMEIDA, 2002; KOMORI et al., 2004).

Outro ponto importante é a adaptabilidade e estabilidade das cultivares ao ambiente e época de semeadura. Dias et al. (2009), estudando genótipos de soja, identificaram materiais mais adequados para o cultivo no Estado do Ceará, baseando-se na adaptabilidade e época adequada de semeadura no Estado.

Segundo Peixoto et al. (2000) ao se optar por uma determinada época de semeadura, o produtor escolhe uma combinação entre a fenologia da cultura e a distribuição dos elementos do clima na região de produção, que poderá resultar em elevado ou reduzido rendimento.

Neste contexto, este trabalho teve por objetivo avaliar cultivares de soja, quanto ao seu desempenho agronômico, em diferentes épocas, visando à indicação do melhor período de semeadura, em Uberlândia-MG.

\section{Material e Métodos}

O experimento foi conduzido em uma área 
experimental localizada na Fazenda Capim Branco (18 52'S; 48 $20^{\circ} \mathrm{W}$ e $805 \mathrm{~m}$ de altitude), pertencente à Universidade Federal de Uberlândia, no município de Uberlândia. Segundo os dados climáticos (1981 a 2008) fornecidos pelo Instituto de Geografia da UFU, Uberlândia (MG) apresenta temperatura média do ar de $22,4^{\circ} \mathrm{C}$, umidade relativa do ar média de $70 \%$ e precipitação pluvial anual média de $1.584 \mathrm{~mm} / \mathrm{ano}$. A área em que foi realizado o experimento situa-se sobre um Latossolo vermelho escuro distrófico, sob cultivo de soja há mais de dez anos.

O período avaliado foi no ano agrícola 2001/2002 com as semeaduras realizadas em quatro épocas: 30 de outubro, 15 de novembro, 14 de dezembro e 31 de dezembro. O delineamento experimental utilizado foi em blocos casualizados, em esquema fatorial 7 (cultivares) x 4 (épocas), com três repetições. A unidade experimental constituiu-se de quatro linhas de 5,0 m, espaçadas de 0,45 m. Considerou-se parcela útil às duas linhas centrais, retirando-se $0,5 \mathrm{~m}$ das extremidades, que constituiu a parcela útil. O procedimento experimental foi igual para todas as épocas de semeadura. Foram avaliadas sete cultivares de soja: DM-118, DM247, DM-339, DM-98C81, DM-Vitória, DM-309 e DM-Nobre. As sementes utilizadas foram de boa qualidade sanitária e fisiológica, apresentando $80 \%$ de germinação.

No preparo da área foram realizadas uma aração e duas gradagens. A semeadura foi manual, semeandose 30 a $40 \%$ a mais da quantidade indicada para cada unidade experimental, de 10 sementes por metro linear. Realizou-se o desbaste das plantas com 10 dias após a emergência, estabelecendo o nível populacional de 300 mil plantas por hectare. A adubação foi de acordo com as recomendações para a cultura (EMBRAPA, 2008) e com base nos resultados das análises do solo, aplicou-se 400 $\mathrm{kg} \cdot \mathrm{ha}^{-1}$ da formulação 02-28-18 $+\mathrm{Zn}$. As sementes foram inoculadas com Bradyrhizobium japonicum, na dosagem de 300 mil células por semente.
Na primeira época de semeadura (30 de outubro) foi necessária a realização de irrigação para possibilitar a germinação das sementes, através do sistema simples de aspersão. Quatro aplicações de Metamidofós foram realizadas, na dosagem de 500 mL.ha ${ }^{-1}$, quando notada a presença de lagarta da soja e percevejos em níveis de controle (NC) e para o controle de plantas daninhas e doenças seguiuse as recomendações de produtos para a cultura (EMBRAPA, 2008).

As características da planta avaliadas foram:

Número de dias para floração: definida como números de dias desde a emergência até a floração, quando $50 \%$ das plantas da parcela útil possuíam pelo menos uma flor aberta.

Número de dias para maturação: Avaliouse o intervalo da emergência até a maturação, considerando $95 \%$ das vagens maduras, ou seja, quando se encontravam no estádio de desenvolvimento R8.

Altura de planta na floração: mensurada através de uma régua graduada considerandose a distância entre a superfície do solo e o ápice da haste principal da planta. Realizou-se este procedimento em 10 plantas tomadas aleatoriamente na parcela útil, no estádio de desenvolvimento R2, apresentando flor aberta em um dos dois últimos nós da haste principal, com a folha completamente desenvolvida.

Altura de planta na maturação: distância em centímetros, entre a superfície do solo e o ápice da haste principal de 10 plantas tomadas aleatoriamente, quando estas se encontravam no estágio reprodutivo $\mathrm{R} 8$, em que $95 \%$ das vagens atingiram a cor de vagem madura, variando com cada cultivar.

Altura de inserção da primeira vagem: distância em centímetros, entre a superfície do solo e a inserção da primeira vagem.

Acamamento: avaliado através de uma escala visual quando as plantas atingiram o estágio 
$\mathrm{R} 8$, recebendo as seguintes notas de acordo com as características: 1 - todas as plantas eretas na unidade experimental; 2 - plantas ligeiramente inclinada ou algumas plantas acamadas; 3 - plantas moderadamente inclinadas ou 25 a $50 \%$ de plantas acamadas; 4 - plantas consideravelmente inclinadas ou 50 a $80 \%$ de plantas acamadas; 5 - todas as plantas prostradas.

Produtividade (kg.ha- ${ }^{-1}$ ): todas as plantas da área útil foram colhidas cuidadosamente, separadas e identificadas para posterior trilhagem. Pesaramse os grãos para cada unidade experimental e calculou-se a produtividade em $\mathrm{kg} \cdot \mathrm{ha}^{-1}$, sendo esta produtividade corrigida para teor de umidade de $13 \%$, conforme a Equação (1):

$$
P F=P I \times \frac{100-U I}{100-U F}
$$

em que: PF: peso final corrigido da amostra; PI: peso inicial da amostra; UI: umidade inicial da amostra; UF: umidade final da amostra (13\%).

Realizaram-se os testes de pressuposições estatísticos para testar a normalidade dos erros e homogeneidade das variâncias e em seguida a análise de variância sem a necessidade de transformação dos dados. O programa estatístico utilizado foi o Sisvar (FERREIRA, 2000).

\section{Resultados e Discussão}

Somente para as características relacionadas ao ciclo da cultura, como dias para maturação e para o florescimento, houve interação entre os fatores estudados: Cultivar e Época. Para as demais variáveis avaliadas identificou-se diferença isolada para cada fator. Para o caráter produtividade, não foi identificado diferença significativa entre as cultivares, porém houve diferenças entre as épocas (Tabela 1).

Tabela 1. Resumo na Análise de variância, apresentando os valores de Quadrado médio e dos Resíduo.

\begin{tabular}{lccccccc}
\hline Variação & G.L. & $\begin{array}{c}\text { PRO } \\
\left(\mathbf{k g ~ h a}^{-1}\right)\end{array}$ & $\begin{array}{c}\text { HM } \\
(\mathbf{c m})\end{array}$ & $\begin{array}{c}\text { HIV } \\
(\mathbf{c m})\end{array}$ & DM & DF & ACAM \\
\hline Cultivar & 6 & $464578,24^{\text {ns }}$ & $1101,62^{*}$ & $94,07^{*}$ & $667,64^{*}$ & $118,93^{*}$ & $1,0406^{\text {ns }}$ \\
Época & 3 & $8160857,71^{*}$ & $2790,44^{*}$ & $19,35^{\text {ns }}$ & $3395,87^{*}$ & $278,00^{*}$ & $7,7182^{*}$ \\
Cultivar* Época & 18 & $362381,93^{\text {ns }}$ & $93,24^{\text {ns }}$ & $23,88^{\text {ns }}$ & $165,77^{*}$ & $11,50^{*}$ & $0,8039^{\text {ns }}$ \\
Bloco & 2 & -- & -- & -- & -- & -- & -- \\
Resíduo médio & 54 & -- & -- & -- & -- & -- & -- \\
Total & 83 & -- & -- & -- & -- & -- & -- \\
c.v. & -- & 19,88 & 9,61 & 23,59 & 1,21 & 0,35 & 55,49 \\
\hline
\end{tabular}

ns,*: não significativo e significativo pelo teste $\mathrm{F}$ a $5 \%$ de probabilidade. PRO: Produtividade; HM: Altura na maturação; HIV: Altura de inserção da primeira vagem; DM: dias para maturação; DF: dias para florescimento e ACAM: acamamento.

Quanto aos dias para maturação, observou-se em todas as cultivares uma redução gradativa, à medida que se retardou a semeadura. Essa redução aconteceu em consequência do encurtamento no período reprodutivo, sensível às variações climáticas decorrentes do atraso da semeadura, principalmente por irregularidades pluviométricas
(BARROS et al., 2003). A cultivar DM118 foi a mais precoce, atingindo a maturação aos 126 dias, apresentando-se de ciclo semi-tardio (Tabela 2). As cultivares DM Nobre, DM309 e DM Vitória foram as que apresentaram o ciclo mais tardio, atingindo o florescimento após os 65 dias e a maturação somente após os 150 dias (Tabelas 2 e 3). Logo, quanto à 
época de semeadura, quanto mais tardia, menos dias serão necessários para atingir tanto o florescimento quanto a maturação (SILVEIRA NETO et al., 2005). Esta relação foi observada em todas as cultivares, em que a DM118, passou do grupo de maturação semi-tardio para o grupo médio quando semeada em dezembro. Para as cultivares de ciclo tardio, como a DM Nobre, que também passou de ciclo tardio para médio, reduzindo seu ciclo em 30 dias, diferindo do encontrado por Barros et al. (2003) e por Pelúzio et al. (2006) que não identificaram diferença no ciclo de diferentes cultivares de soja quando semeadas em épocas diferentes, no estado do Tocantins. Nas tabelas 2 e 3, pode-se observar também que quanto mais tardio a semeadura, menores são as diferenças entre o ciclo das cultivares.

Tabela 2. Médias de números de dias para maturação de sete cultivares de soja em quatro épocas de semeadura no município de Uberlândia, MG no ano agrícola de 2001/2002 .

\begin{tabular}{lcccc}
\hline & \multicolumn{4}{c}{ ÉPOCA DE SEMEADURA } \\
\cline { 2 - 5 } CULTIVARES & $\mathbf{3 0 / \text { out }}$ & $\mathbf{1 5 / \mathbf { n o v }}$ & $\mathbf{1 4 / \mathbf { d e z }}$ & $\mathbf{3 1 / d e z}$ \\
\hline DM-118 & $126,00 \mathrm{e} \mathrm{A}$ & $125,00 \mathrm{e} \mathrm{A}$ & $117,00 \mathrm{~d} \mathrm{~B}$ & $117,00 \mathrm{c} \mathrm{B}$ \\
DM-247 & $144,50 \mathrm{~d} \mathrm{~A}$ & $136,50 \mathrm{~d} \mathrm{~B}$ & $127,00 \mathrm{~b} \mathrm{C}$ & $117,00 \mathrm{c} \mathrm{D}$ \\
DM-339 & $144,58 \mathrm{~cd} \mathrm{~A}$ & $137,5 \mathrm{~cd} \mathrm{~B}$ & $127,00 \mathrm{~b} \mathrm{C}$ & $117,00 \mathrm{c} \mathrm{D}$ \\
DM-98C81 & $149,33 \mathrm{bc} \mathrm{A}$ & $149,00 \mathrm{~b} \mathrm{~A}$ & $122,00 \mathrm{c} \mathrm{C}$ & $126,00 \mathrm{~b} \mathrm{~B}$ \\
DM-Vitória & $152,08 \mathrm{ab} \mathrm{A}$ & $141,00 \mathrm{c} \mathrm{B}$ & $136,00 \mathrm{a} \mathrm{C}$ & $114,00 \mathrm{c} \mathrm{D}$ \\
DM-309 & $148,83 \mathrm{ab} \mathrm{B}$ & $153,00 \mathrm{~b} \mathrm{~A}$ & $126,75 \mathrm{~b} \mathrm{~B}$ & $126,25 \mathrm{~b} \mathrm{~B}$ \\
DM-Nobre & $153,66 \mathrm{a} \mathrm{B}$ & $170,00 \mathrm{a} \mathrm{A}$ & $122,00 \mathrm{c} \mathrm{D}$ & $133,00 \mathrm{a} \mathrm{C}$ \\
\hline DMS cultivar & 4,069 & & \\
DMS época & 3,520 & & & \\
\hline
\end{tabular}

*Médias seguidas de mesma letra minúscula na coluna e maiúscula na linha, não diferem entre si pelo teste de Tukey, a $5 \%$ de probabilidade.

Tabela 3. Médias de números de dias para floração de sete cultivares de soja em quatro épocas de semeadura no município de Uberlândia, MG no ano agrícola de 2001/2002.

\begin{tabular}{lcccc}
\hline & \multicolumn{4}{c}{ ÉPOCA DE SEMEADURA } \\
\cline { 2 - 5 } CULTIVARES & $\mathbf{3 0 / 0 u t}$ & $\mathbf{1 5 / n o v}$ & $\mathbf{1 4 / d e z}$ & $\mathbf{3 1 / d e z}$ \\
\hline DM-118 & $57,00 \mathrm{f} \mathrm{C}$ & $60,00 \mathrm{e} \mathrm{A}$ & $55,00 \mathrm{c} \mathrm{D}$ & $58,00 \mathrm{e} \mathrm{B}$ \\
DM-247 & $64,00 \mathrm{e} \mathrm{B}$ & $65,00 \mathrm{~d} \mathrm{~A}$ & $55,00 \mathrm{c} \mathrm{D}$ & $58,00 \mathrm{e} \mathrm{C}$ \\
DM-309 & $67,00 \mathrm{c} \mathrm{A}$ & $65,00 \mathrm{~d} \mathrm{~B}$ & $60,75 \mathrm{a} \mathrm{D}$ & $62,25 \mathrm{c} \mathrm{C}$ \\
DM-Vitória & $65,00 \mathrm{~d} \mathrm{~B}$ & $68,00 \mathrm{~b} \mathrm{~A}$ & $61,00 \mathrm{a} \mathrm{C}$ & $61,00 \mathrm{~d} \mathrm{C}$ \\
DM-339 & $69,00 \mathrm{~b} \mathrm{~A}$ & $65,66 \mathrm{c} \mathrm{B}$ & $60,00 \mathrm{~b} \mathrm{D}$ & $61,00 \mathrm{~d} \mathrm{C}$ \\
DM-98C81 & $69,00 \mathrm{~b} \mathrm{~A}$ & $68,00 \mathrm{~b} \mathrm{~B}$ & $61,00 \mathrm{a} \mathrm{D}$ & $63,00 \mathrm{~b} \mathrm{C}$ \\
DM-Nobre & $74,00 \mathrm{a} \mathrm{A}$ & $69,00 \mathrm{a} \mathrm{B}$ & $60,00 \mathrm{~b} \mathrm{D}$ & $65,00 \mathrm{a} \mathrm{C}$ \\
\hline
\end{tabular}

*Médias seguidas de mesma letra minúscula na coluna e maiúscula na linha, não diferem entre si pelo teste de Tukey a $5 \%$ de probabilidade.

Para a altura de inserção de vagens (Tabela 4) a cultivar DM Vitória foi a que apresentou a maior identificou-se diferença entre as cultivares, em que inserção, $22 \mathrm{~cm}$, porém todas elas apresentaram 
valores suficientes para a realização de colheita mecânica. Segundo Sediyama, Teixeira e Reis (2009), para que não haja perda na colheita pela barra de corte, a altura mínima da primeira vagem deve ser de 10 a 12 centímetros em solos de topografia plana e aproximadamente 15 centímetros em terrenos mais inclinados. Nas condições do experimento nenhuma cultivar teria problemas de perdas na colheita, em topografia mais plana, uma vez que todas tiveram altura de inserção da primeira vagem superior a 12 cm. Para terrenos inclinados, a cultivar DM- 118, não é recomendada, pois suas médias estão próximas e/ou abaixo do mínimo exigido. A altura de plantas apresentou relação com a altura de inserção da primeira vagem. A cultivar DM118 apresentou menor altura, porém ainda superior aos $50 \mathrm{~cm}$ indicado para a cultura (URBEN FILHO; SOUZA, 1993) como critério para a seleção de novos cultivares.

Tabela 4. Médias originais de altura de inserção de vagem e de planta na maturação em sete cultivares de soja no município de Uberlândia, MG, no ano agrícola de 2001/2002 .

\begin{tabular}{lcc}
\hline CULTIVAR & ALTURA DE INSERÇÃO DE VAGEM (cm) & ALTURA DE MATURAÇÃO (cm) \\
\hline DM-118 & $13,25 \mathrm{~b}$ & $78,69 \mathrm{~d}$ \\
DM-309 & $14,27 \mathrm{~b}$ & $86,46 \mathrm{~cd}$ \\
DM-339 & $16,97 \mathrm{~b}$ & $90,07 \mathrm{c}$ \\
DM-247 & $17,77 \mathrm{ab}$ & $94,12 \mathrm{bc}$ \\
DM-98C81 & $17,36 \mathrm{ab}$ & $95,54 \mathrm{abc}$ \\
DM-Nobre & $16,87 \mathrm{~b}$ & $103,71 \mathrm{ab}$ \\
DM-Vitória & $21,98 \mathrm{a}$ & $106,21 \mathrm{a}$ \\
\hline DMS & 4,99 & 11,24 \\
\hline
\end{tabular}

*Médias seguidas de mesma letra minúscula, não diferem entre si pelo teste de Tukey, a 5\% de probabilidade.

Com relação à época de semeadura (Tabela 5), nas primeiras épocas, as cultivares apresentaram maior altura, $100 \mathrm{~cm}$ em média, enquanto que na semeadura mais tardia a altura média foi de apenas $77 \mathrm{~cm}$; situação semelhante a que Peixoto et al. (2000) encontraram trabalhando com três cultivares de soja de diferentes ciclos em três épocas de semeadura, mas diferente da encontrada por Barros et al. (2003) que não encontraram diferenças significativas da altura com relação a época de semeadura. Plantas de ciclo mais tardio, semeadas mais cedo, como a DM-Nobre, tenderam a um crescimento maior devido a um maior período vegetativo; ocasionado pela característica de período juvenil longo, ou seja, demandando maior tempo para atingir o estádio reprodutivo, tornando-se assim suscetível ao acamamento, o que pode comprometer a produtividade, a qualidade sanitária das sementes e dificultar a colheita mecanizada.

Segundo Sediyama, Teixeira e Reis (2005), as plantas altas e, ou o caule muito fino tendem ao acamamento com maior facilidade. A altura das plantas tanto na floração, quanto na maturação foram maiores nas cultivares que apresentaram maiores níveis de acamamento (Tabela 5), como é o caso da cultivar DM- Nobre.

Nota-se que as plantas que mais cresceram, nos períodos de semeadura 1,2 de 3 foram as que mais se acamaram (Tabela 5). Portanto identificou-se uma relação entre altura de plantas e acamamento, no caso da última época de semeadura em que as plantas menos desenvolveram, foi onde ocorreu menor índice de acamamento. 
Tabela 5. Médias originais de altura de inserção de vagem e de planta no florescimento, e notas para o acamamento em quatro épocas de semeadura no município de Uberlândia, MG, no ano agrícola de $2001 / 2002$.

\begin{tabular}{lccc}
\hline Época Semeadura & $\begin{array}{c}\text { Altura de Inserção } \\
\text { de Vagem } \mathbf{( c m )}\end{array}$ & $\begin{array}{c}\text { Altura na } \\
\text { Maturação }(\mathbf{c m})\end{array}$ & $\begin{array}{c}\text { Acamamento } \\
\mathbf{( 1 ~ a ~ 5 ) ~}\end{array}$ \\
\hline $30 /$ out & $18,05 \mathrm{a}$ & $98,67 \mathrm{ab}$ & $1,57 \mathrm{ab}$ \\
$15 / \mathrm{nov}$ & $17,15 \mathrm{a}$ & $103,92 \mathrm{a}$ & $1,88 \mathrm{bc}$ \\
$14 / \mathrm{dez}$ & $16,77 \mathrm{a}$ & $94,28 \mathrm{~b}$ & $2,45 \mathrm{c}$ \\
$31 / \mathrm{dez}$ & $15,73 \mathrm{a}$ & $77,29 \mathrm{c}$ & $1,00 \mathrm{a}$ \\
\hline $\mathrm{DMS}$ & 3,26 & 7,35 & 0,78 \\
\hline
\end{tabular}

*Médias seguidas de mesma letra minúscula, não diferem entre si pelo teste de Tukey, a 5\% de probabilidade.

Quanto à produtividade, não houve interação entre os fatores em estudo, havendo diferença apenas entre as épocas de semeadura (Tabela1). Para as duas primeiras épocas (30/10 e 15/11) não houve diferença entre as cultivares, portanto a partir da semeadura em 14/12 as cultivares DM118, 98C81 e DM Vitória tiveram queda na produtividade, quando comparadas com a semeadura antecipada, situação semelhante ao que Nunes Júnior et al. (2000) encontraram em Anápolis$\mathrm{GO}$, onde foi observado redução na produtividade a medida que se retardou a semeadura.

A semeadura no final de dezembro apresentou as menores produtividades, tanto para as cultivares de ciclo precoce quanto para as de ciclo tardio (Tabela 6), evidenciando uma queda brusca no rendimento médio, fato este esperado, devido ao efeito que ocasiona a semeadura tardia em que proporciona um florescimento precoce com encurtamento do ciclo vegetativo, diminuição do porte e consequentemente, queda na produtividade. Tudo isso condicionado pelo ambiente favorável para indução floral, ou seja, fotoperíodo ideal. Isto mostra a importância da época de semeadura da soja para a obtenção de boas produtividades. Resultado semelhante foi encontrado por Silveira Neto et al. (2005), os quais obtiveram maior produtividade na primeira época de semeadura, 28 de novembro, em relação à outras quatros épocas mais tardias, em três municípios.

Tabela 6. Médias originais de produtividade em kg.ha-1 de sete cultivares de soja em quatro épocas de semeadura no município de Uberlândia, MG, no ano agrícola de 2001/2002.

\begin{tabular}{|c|c|c|c|c|}
\hline \multirow[t]{2}{*}{ CULTIVARES } & \multicolumn{4}{|c|}{ ÉPOCA DE SEMEADURA } \\
\hline & 30/out & $15 /$ nov & $14 / \mathrm{dez}$ & 31/dez \\
\hline DM-Nobre & $2435,18 \mathrm{aA}$ & $2500,00 \mathrm{aA}$ & $1842,59 \mathrm{aAB}$ & $1259,26 \mathrm{aB}$ \\
\hline DM-247 & $2546,30 \mathrm{aA}$ & $2246,29 \mathrm{abA}$ & $1861,11 \mathrm{aA}$ & $1592,59 \mathrm{aA}$ \\
\hline DM-118 & $2166,66 \mathrm{aB}$ & $3675,92 \mathrm{bA}$ & $2157,41 \mathrm{aB}$ & $1120,37 \mathrm{aC}$ \\
\hline DM-98C 81 & $3046,29 \mathrm{aA}$ & $2694,44 \mathrm{abAB}$ & $1574,07 \mathrm{aC}$ & $1833,33 \mathrm{aBC}$ \\
\hline DM-309 & 2629,63 aA & $3222,22 \mathrm{abA}$ & $2462,96 \mathrm{aAB}$ & $1620,37 \mathrm{aB}$ \\
\hline DM-Vitória & $3138,88 \mathrm{aA}$ & 2962,96 abAB & $1990,74 \mathrm{aBC}$ & $1916,67 \mathrm{aC}$ \\
\hline DM-339 & $2953,71 \mathrm{aA}$ & $2935,18 \mathrm{abA}$ & 2629,63 aA & $1555,55 \mathrm{aB}$ \\
\hline DMS cultivar & 1151,86 & & & \\
\hline DMS época & 997,26 & & & \\
\hline
\end{tabular}

*Médias seguidas de mesma letra minúscula na coluna e maiúscula na linha, não diferem entre si pelo teste de Tukey, a $5 \%$ de probabilidade. 
As cultivares DM-339 e DM-309 são boas opções para serem semeadas no município de Uberlândia-MG, porém devem ser semeadas até 15 de novembro para que se obtenham maiores rendimentos.

\section{Conclusões}

A época de semeadura resulta em diferença na maioria das características agronômicas da cultura, havendo decréscimo de altura de planta e número de dias para a floração, à medida que se atrasa a semeadura.

Para a região de Uberlândia, o ideal é que a semeadura da soja seja realizada até 15 de novembro para as cultivares DM118, DM 98C81 e DM Vitória e para as demais cultivares avaliadas até 14 de dezembro.

\section{Agradecimentos}

Ao Instituto de Ciências Agrárias da Universidade Federal de Uberlândia e a Fundação de Apoio e Amparo a Pesquisa do Estado de Minas Gerais pelo apoio financeiro e incentivo a pesquisa.

\section{Referências}

BARROS, H.; PELÚZIO, J. M.; SANTOS, M. M.; BRITO, E. L.; ALMEIDA, R. D. Efeito das épocas de semeadura no comportamento de cultivares de soja, no sul do estado do Tocantins. Revista Ceres, Viçosa, MG, v. 50, n. 291, p. 565-572, 2003.

CÂMARA, G. M. S. Ecofisiologia da cultura da soja. In: CÂMARA, G. M. S.; MARCOS FILHO, J.; OLIVEIRA, E. A. M. In: SIMPÓSIO SOBRE A CULTURA E PRODUTIVIDADE DA SOJA. PIRACICABA, 9., 1992, São Paulo. Anais... São Paulo: FEALQ, 1992. p. 19-28.

CÂMARA， G. M. S.; HEIFFIG， L. S. Fisiologia, ambiente e rendimento da cultura da soja. In: CÂMARA, G. M. S. Soja: tecnologia da produção II. Piracicaba: FEALQ, 2000. p. 81-119.

DIAS, F. T. C. Adaptabilidade e estabilidade da produção de cultivares de soja no estado do Ceará. Fortaleza, CE. 2007. Monografia (Curso de Agronomia) - Universidade
Federal do Ceará, Ceará.

DIAS, F. T. C.; PITOMBEIRA, J. B.; TEÓFILO, E. M.; BARROS, F. S. Adaptabilidade e estabilidade fenotípica para o caráter rendimento de grãos em cultivares de soja para o Estado do Ceará. Revista Ciência Agronômica, Fortaleza, v. 40, n. 1, p. 129-134, 2009.

EMPRESA BRASILEIRA DE PESQUISA AGROPECUÁRIA - EMBRAPA. Tecnologias de produção de soja - Região Central do Brasil - 20092010. Londrina: EMBRAPA Agropecuária Oeste, 2008. 262 p. (Sistemas de Produção / EMBRAPA Soja, n. 13).

FERREIRA, D. F. Sistema de análises de variância para dados balanceados. Lavras: UFLA, 2000. (SISVAR 4. 1. pacote computacional).

KOMORI, E.; HAMAWAKI, O. T.; ALMEIDA, E. F. Época de semeadura da Soja na Região do Triângulo Mineiro. Revista Bioscience Journal, Uberlândia, MG, v. 36, n. 3, p. 10-15, 2002.

KOMORI, E.; HAMAWAKI, O. T.; SOUZA, M. P.; SHIGIHARA, D.; BATISTA, A. M. Influência da época de semeadura e população de plantas sobre características agronômicas na cultura da soja. Revista Bioscience Journal, Uberlândia, MG, v. 20, n. 3, p. 13-19, 2004.

NUNES JÚNIOR, J. J.; PIMENTA, C. B.; PEREIRA, R. G.; OLIVEIRA, L. J. Avaliação de onze cultivares de soja em quatro épocas de semeadura e em três densidades de plantio. In: REUNIAO DE PESQUISA DE SOJA DA REGIAO CENTRAL DO BRASIL, 2., Cuiabá. Resumos... Londrina: Embrapa Soja, 2000. p. 156.

PEIXOTO, C. P.; CÂMARA, G. M. S.; MARTINS, M. C.; MARCHIORI, L. F. S.; GUERZONI, R. A.; MATTIAZZI, P. Sowing date and plant density of soybean yield components and grain yield. Scientia Agricola, Piracicaba, v. 57, n. 1, p. 153-162, 2000.

PELÚZIO, J. M.; FIDELIS, R. R.; ALMEIDA JÚNIOR, D.; BARBOSA, V. S.; RICHTER, L. H. M.; SILVA, R. R. da; AFFÉRRI, F. S. Desempenho de cultivares de soja, em duas épocas de semeadura, no sul do estado do Tocantins. Revista Bioscience Journal, Uberlândia, v. 22, n. 2, p. 69-74, 2006.

ROCHA, M. M.; VELHO, N. A.; LOPES, A. C. A.; UNÊDA-TREVISOLI, S. H.; MAIA, M. C. C. Correlações entre parâmetros de adaptabilidade e estabilidade da produtividade de óleo em soja. Ciência Rural, Santa Maria, v. 36, n. 3, p. 772-777, 2006.

RODRIGUES, O.; DIDONET, A. D.; LHAMBY, J. C. B.; BERTAGNOLLI, P. F.; LUIZ, J. S. da. Resposta quantitativa do florescimento da soja à temperatura e ao fotoperíodo. Pesquisa Agropecuária Brasileira, Brasília, v. 36, n. 3, p. 431-437, 2001. 
SCHONINGER, E. L.; LANGE, A.; SILVA, A. F.; LEMKE, A. F.; MONTEIRO, S.; SILVA, J. A. N. Atributos químicos do solo e produtividade da cultura de soja em área de semeadura direta após calagem superficial. Revista Semina: Ciências Agrárias, Londrina, v. 31, p. 1253-1262, 2010. Suplemento 1.

SEDIYAMA, T. Tecnologias de produção e usos da soja. Londrina: Editora Mecenas, 2009. 314 p.

SEDIYAMA, T.; TEIXEIRA, R. C.; REIS, M. S. Melhoramento da soja. In: BORÉM, A. (Ed.). Melhoramento de espécies cultivadas. Viçosa: Editora UFV, 2005. p. 897-930.

SILVEIRA NETO, A. N.; OLIVEIRA, A. B.; GODOI, C. R. C.; PRADO, C. L. O.; PINHEIRO, J. B. Desempenho de linhagens de soja em diferentes locais e épocas de semeadura em Goiás. Pesquisa Agropecuária Tropical, Goiânia, v. 35, n. 2, p. 103-108, 2005.

URBEN FILHO, G.; SOUZA, P. I. M. Manejo da cultura da soja sob cerrado: época, densidade e profundidade de semeadura. In: ARANTES, N. E.; SOUZA, P. I. M. (Ed.). Cultura da soja nos cerrados. Belo Horizonte: POTAFOS, 1993. 535 p. 
